\title{
Correction to: Synthesis, spectroscopic characterization and in vitro anticancer activity of new platinum(II) complexes with some thione ligands in the presence of triethylphosphine
}

\author{
Mohammed Yagoub Jomaa • Muhammed Altaf - Saeed Ahmad • \\ Gaurav Bhatia $\cdot$ Jatinder Singh $\cdot$ Saleh Altuwaijri - Anvarhusein A. Isab
}

Published online: 11 August 2020

(C) Springer Nature B.V. 2020

\section{Correction to:}

Biometals (2017) 30:787-795

https://doi.org/10.1007/s10534-017-0047-5

Biometals (2015) 28:827-844

https://doi.org/10.1007/s10534-015-9869-1

Biometals (2014) 27:1115-1136

https://doi.org/10.1007/s10534-014-9771-2

Due to an unfortunate turn of events, the main affiliation of Dr. Saleh Altuwaijri was omitted from

The original articles can be found online at https:// doi.org/10.1007/s10534-017-0047-5, https://doi.org/10.1007/ s10534-015-9869-1, https://doi.org/10.1007/s10534-014-9771-2.

M. Y. Jomaa · A. A. Isab (ه)

Department of Chemistry, King Fahd University of Petroleum and Minerals, Dhahran 31261, Saudi Arabia e-mail: aisab@kfupm.edu.sa

M. Altaf

Center of Research Excellence in Nanotechnology, King Fahd University of Petroleum and Minerals,

Dhahran 31261, Saudi Arabia

\section{S. Ahmad}

Department of Chemistry, College of Sciences and Humanities, Prince Sattam Binin Abdulaziz University, Al-Kharj 11942, Saudi Arabia the above mentioned three articles. The complete affiliations are published below and should be treated as definitive.

Publisher's Note Springer Nature remains neutral with regard to jurisdictional claims in published maps and institutional affiliations.

G. Bhatia · J. Singh

Department of Molecular, Biology \& Biochemistry, Guru

Nanak Dev University, Amritsar 143005, India

S. Altuwaijri

Clinical Research Laboratory, SAAD Research

Development Center, SAAD Specialist Hospital,

Al-Khobar 31952, Saudi Arabia

S. Altuwaijri

Veterinary Medicine, College of Agriculture and

Veterinary Medicine, Qassim University,

Buraydah 51452, Saudi Arabia 